\title{
IDENTIFICAÇÃO E AVALIAÇÃO DE RIZOBACTÉRIAS ISOLADAS DE RAÍZES DE MILHO (')
}

\author{
ELIAMAR APARECIDA NASCIMBÉM PEDRINHO (2); \\ RENATO FERNANDES GALDIANO JÚNIOR (2); JOÃO CARLOS CAMPANHARO $\left({ }^{2}\right)$; \\ LÚCIA MARIA CARARETO ALVES $\left({ }^{2}\right)$; ELIANA GERTRUDES DE MACEDO LEMOS $\left({ }^{*}\right)$
}

\begin{abstract}
RESUMO
Estudos sobre a atividade microbiológica que ocorre na rizosfera de diversos vegetais levaram ao descobrimento de grupos de microrganismos importantes para o desenvolvimento vegetal. Dentre eles estão as rizobactérias que são capazes de colonizar as raízes, estimulando-a diretamente ou beneficiando o crescimento e o desenvolvimento de diversas plantas. Estas bactérias são chamadas Rizobactérias Promotoras de Crescimento em Plantas (RPCP). Este trabalho teve o objetivo de isolar, identificar, testar a capacidade da solubilização de fosfato e a produção de ácido indol acético (AIA) de bactérias que habitam a rizosfera de plantas de milho. A análise parcial do gene 16S rRNA dos 58 isolados possibilitou a identificação dos gêneros, Bacillus, Burkholderia e Azospirillum, sendo os mais frequentes totalizando 68\% dos isolados, seguidos de Sphingomonas, Pseudomonas, Herbaspirillum, Pantoea , Bosea. Desses, 27 apresentaram a capacidade de solubilização do fosfato e 18 foram positivos no teste colorimétrico para detecção de produção do AIA. A partir destes resultados, selecionou-se um organismo pertencente ao gênero Sphingomonas para ser testado em casa de vegetação como promotor de crescimento com as estirpes de Azospirillum brasilense (AbV5 e AbV6). As plantas foram avaliadas quanto à altura aos vinte e setenta dias após a germinação e a massa seca da parte aérea (MSPA)e parte radicular (MSPR) foi quantificada após setenta dias no encerramento do experimento. Os resultados das análises do isolado pertencente ao gênero Sphingomonas foram estatisticamente semelhantes às estirpes AbV5 e AbV6 na planta de milho indicando que este microrganismo possui potencial para ser utilizado como RPCP.
\end{abstract}

Palavras-chaves: RPCP, ácido indol acético, solubilização de fosfato, Sphingomonas spp.

\author{
ABSTRACT \\ IDENTIFICATION AND EVALUATION OF BACTERIA ISOLATED FROM ROOTS OF MAIZE
}

Researches about microbiological activity on many plants rizosphere led to the discovery of groups of important microrganisms for plants development. Among them there are the rizobacteria able to colonize the roots, stimulating directly or benefiting many plants. These bacteria are called Growth Promoting Rizobacteria or GPR. In view of this, the present study was performed, aiming to isolate, identify and test phosphate solubilization and acetic indol acid (AIA) production in bacteria that lives in maize roots. The partial analysis of the 16S rRNA gene of the 58 isolates enabled the identification of the genres Bacillus, Burkholderia and Azospirillum, and the most frequent totaling $86 \%$ of the isolates, followed by Sphingomonas, Pseudomonas, Herbaspirillum, Pantoea and Bosea. Out of the 58 isolates, 27 showed the capacity of phosphate solubilization and 18 were positive to the AIA production colorimetric detection test. From these results was chosen an organism belonging to the genre Sphingomonas to be tested at greenhouse as growth promoter with the strains Azospirillum brasiliense (AbV5 e AbV6). The plants were assessed twenty and seventy days after germination. Dry mass of shoot and root parts were quantified after seventy days at the end of the experiment. Statistical analysis indicated by the program Statistix v.9.0 showed that the isolates belonging to the genre Sphingomonas presented similar results as shown by strains AbV5 and AbV6 on maize plant. This microorganism may become a promising one to be used as a GPR.

Key words: GPR, indol acetic acid, phosphate solublization, Sphingomonas spp.

(1) Recebido para publicação em 5 de dezembro de 2008 e aceito em 20 de abril de 2010.

$\left(^{2}\right)$ Universidade Estadual Paulista, Faculdade de Ciências Agrárias e Veterinárias,UNESP, Departamento de tecnologia, Via de acesso Prof. D. Castellane, s/n., 14884-900 Jaboticabal (SP). E-mail: eliamar.pedrinho@gmail.com; renatofgaldianojr@yahoo.com.br; jccamp@fcav.unesp.br; lmcalves@fcav.unesp.br, egerle@fcav.unesp.br (*) Autora correspondente. 


\section{INTRODUÇÃO}

O milho (Zea mays L.) pertence à família Poaceae (BoRÉM, 1999), sendo considerada uma importante cultura tropical, e constituindo uma das principais fontes de calorias para milhões de pessoas no México, na América Central e na América do Sul.

Esse cereal tem grande importância econômica no Brasil, pois além de ser utilizado na alimentação humana, na alimentação animal e na indústria, é também um importante produto de exportação (AGRIANUAL, 2004). O Estado de São Paulo está entre os Estados brasileiros que mais produzem este cereal, na forma verde para consumo humano e animal.

Devido ao uso crescente da quantidade de fertilizantes nitrogenados e fosfatados necessários à produção agrícola, a alta exigência energética para a produção dos fertilizantes, e ao impacto ambiental provocado pela lixiviação destes produtos, objetiva-se a diminuição da utilização dos fertilizantes minerais pela otimização de alguns processos naturais. Pelo menos, parcialmente, as necessidades das plantas poderiam ser supridas por processos como: fixação biológica de nitrogênio em plantas não-leguminosas e a solubilização de fosfato inorgânico pelas bactérias.

Os hormônios vegetais (auxinas, citocininas, giberelinas, etileno e ácido abscísico) são substâncias orgânicas que desempenham funções na regulação do crescimento em plantas (RAVEN et al., 2001). A principal auxina de ocorrência natural é denominada de ácido indol-acético (AIA). Diversos microrganismos, como bactérias e fungos no solo e ou associados às plantas, sintetizam hormônios de crescimento idênticos aos encontrados nas plantas, dentre eles o AIA.

Em plantas, o AIA microbiano produzido por bactérias do gênero Azospirillum spp, Alcaligenes faecalis, Klebsiella $s p$, Enterobacter sp, Xanthomonas sp, Herbaspirillum seropedicae, Rhizobiumspp e Bradyrhizobium spp tem sido relacionado ao estímulo de crescimento, enquanto os produzidos pelas espécies Pseudomonas savastanoi, P. syringae, Agrobacterium tumefaciens e A. rhyzogenes às patogênicas, (PATTEN e GLICK, 1996).

Acredita-se que um microrganismo pode selecionar uma rota em particular para a biosíntese de AIA, dentre as várias que possui, de acordo com o ambiente. Relata-se também à existência de mais de uma rota para a síntese de AIA em muitas bactérias, sendo a maioria delas via triptofano (PATTEN e GLICK, 1996).

Assim, o principal objetivo deste estudo foi identificar e selecionar microrganismos provenientes da rizosfera de plantas de milho (Zea mays L.), na região de Vargem Grande do Sul, (SP), Brasil, com potencial para uso como biofertilizantes.

\section{MATERIAL E MÉTODOS}

As raízes utilizadas para isolamento foram de plantas de milho Híbrido Impacto coletado com 153 dias, em Vargem Grande do Sul (SP). Para isolamento e cultivo dos microrganismos seguiu-se o protocolo descrito por DöBEREINER (1995). Em sequência detectouse a capacidade in vitro de solubilizar fosfato por meio da inoculação em meio NBRIP (NAUTIYAL, 1999) contendo fosfato insolúvel.

A presença de halo ao redor das colônias considerado indicativo de solubilização do fosfato foi observada em dias diferentes durante quinze dias em cultura incubada a $28{ }^{\circ} \mathrm{C}$. Estas colônias foram estocadas a $-80{ }^{\circ} \mathrm{C}$ em meio DYGS suplementado de glicerol a $20 \%$.

Para extração do DNA utilizou-se o método proposto por MARMUR, (1961), em seguida identificados pelo sequenciamento parcial do gene 16S rRNA, utilizando oligonucleotídeos específicos fD1 e rD1 (Weisburg, 1991). As sequências obtidas foram submetidas à análise de similaridade de nucleotídeos com o banco de dados GenBank para que pudessem ser identificadas e classificadas. Essas sequências estão entre $92 \%$ e $98 \%$ de similaridade quando comparadas às sequências do banco de dados.

Os isolados foram avaliados quanto à capacidade de sintetizar in vitro ácido indol-acético (AIA) pelo método quantitativo colorimétrico (GORDON e WEBER, 1951) após serem cultivados em meio de cultura DYGS suplementado com $100 \mu \mathrm{g} / \mathrm{mL}$ de triptofano. As bactérias foram avaliadas em três estágios de crescimento quando a $\mathrm{DO}_{600}$ (Densidade ótica $600 \mathrm{~nm}$ ) dos cultivos atingiram os valores de $0,810^{8} \mathrm{UFC}, 1,510^{10} \mathrm{UFC}$ e $\geq 3,510^{12} \mathrm{UFC}$ ajustando-se pela adição de solução salina $0,85 \%$.

Oexperimento de inoculação foi realizado em casa de vegetação e os parâmetros avaliados correspondem à biomassa seca e à altura da planta, sendo a seguinte ordem: primeiramente as sementes de milho, Híbrido Impacto, sem tratamento, foram desinfetadas superficialmente pela aplicação de etanol $70 \%$, por 3 vezes durante 5 minutos, em seguida embebidas em hipoclorito de sódio a $2 \%$ por 5 minutos, lavados várias vezes com água deionizada. Após esse procedimento ficaram embebidas em água estéril por duas horas.

O solo utilizado neste experimento foi caracterizado como Latossolo Vermelho com as seguintes características $\mathrm{pH}=4,8$, M.O. $=16 \mathrm{~g} \mathrm{dm}^{-3}, \mathrm{P}=24$ $\mathrm{mg} \mathrm{dm}{ }^{-3}, \mathrm{~K}=1,1, \mathrm{Ca}=15, \mathrm{Mg}=3, \mathrm{H}+\mathrm{Al}=31, \mathrm{SB}=19, \mathrm{~T}=50$ mmol $\mathrm{dm}^{-3}$ e $\mathrm{V} \%=38$. A semeadura foi realizada em vasos de 5L com quatro sementes por vaso. Após a emergência, realizou-se o desbaste mantendo-se apenas uma planta por vaso. 
Os tratamentos foram inoculados com $100 \mu \mathrm{L}$ da suspensão bacteriana a $10^{8} \mathrm{ufcs} / \mathrm{mL}^{-1}$ para o controle positivo AbV5 e AbV6 (Azospirillum brasilense) e para o isolado de Sphingomonas spp aos cinco dias após germinação. Aavaliação de desenvolvimento das plantas foi feita aos 70 dias, no estágio de floração, mediante a obtenção da massa seca das raízes e da parte aérea das plantas submetidas à inoculação e dos controles.

O delineamento experimental utilizado foi em blocos casualizados com sete repetições constituído de três vasos por repetição. Para a análise estatística, utilizou-se o programa Statistix v. 9.0. A análise da variância foi realizada com 5\% de significância e as médias analisadas pelo teste de Tukey a $5 \%$.

\section{RESULTADOS E DISCUSSÃO}

Por meio de métodos para o isolamento de bactérias diazotróficas de plantas não leguminosas, foram obtidos 58 isolados das raízes de plantas sadias de milho, colhidas com 153 dias na região de Vargem Grande do Sul (SP), Brasil.

Quando os isolados foram avaliados quanto à capacidade de solubilizar fosfato pelo uso do meio NBRIP, somente em 27 deles havia tal capacidade observada pela presença de um halo ao redor da colônia. Esses halos foram observados com 12 horas, 48 horas e com quinze dias de cultivo bacteriano; nas primeiras 12 horas verificou-se somente a presença ou ausência na formação dos halos e nos outros períodos mediu-se o diametro dos halos (Tabela 1). As bactériaspadrão AbV5 e Abv6 não foram capazes de solubilizar o fosfato nessas condições, por outro lado, na grande maioria dos isolados (18) havia a formação do halo já com 48 horas de cultivo, variando de 0,8 a $21 \mathrm{~mm}$. Após 15 dias de cultivo, em todos os isolados havia halos, com diâmetros variando de 12 a $55 \mathrm{~mm}$.

Desse modo, os isolados positivos para a prova de solubilização foram classificados pelo sequenciamento parcial do gene do $16 \mathrm{~S}$ rRNA (Tabela 2). Observou-se que os isolados pertenciam aos gêneros Bacillus, Burkholderia, Sphingomonas, Pantoea e Azospirillum. Esses resultados revelam a diversidade de microrganismos nas raízes de milho e a diversidade de bacterias solubilizadoras de fosfato, como já descrito na literatura. Nesse aspecto, MCinRoy e KloepPeR (1991) observaram que plantas sadias de milho contêm uma microflora bacteriana diversificada, sendo o número de gêneros isolados do caule e da raiz maior do que o observado na rizosfera dessas mesmas plantas.

Por outro lado, Rodríguez e Fraga (1999), comprovaram a capacidade de vários gêneros bacterianos em solubilizar fosfato inorgânico, dentre eles os observados neste trabalho. Dos gêneros constatados
Tabela 1. Solubilização de fosfato em meio NBRIP. Halos avaliados com 12 e 48 horas de crescimento e 15 dias. Onde $\mathrm{N}$ ausência da formação de halo e $\mathrm{S}$ presença do halo de solubilização

\begin{tabular}{|c|c|c|c|}
\hline \multirow{3}{*}{$\begin{array}{l}\text { Isolados } \\
\text { Positivos }\end{array}$} & \multicolumn{3}{|c|}{ Tempo de cultivo } \\
\hline & 12 horas & 48 horas & 15 dias \\
\hline & $\begin{array}{l}\text { Presença de } \\
\text { halos }\end{array}$ & $\begin{array}{c}\text { Tamanho dos } \\
\text { halos }\end{array}$ & $\begin{array}{c}\text { Tamanho dos } \\
\text { halos }\end{array}$ \\
\hline & & $-n$ & - \\
\hline AbV5 & $\mathrm{N}$ & $\mathrm{N}$ & $\mathrm{N}$ \\
\hline AbV6 & $\mathrm{N}$ & $\mathrm{N}$ & $\mathrm{N}$ \\
\hline R4.1 & $\mathrm{N}$ & 12 & 34 \\
\hline R4.4 & $\mathrm{S}$ & 18 & 50 \\
\hline $\mathrm{R} 4.5$ & $\mathrm{~S}$ & 0,8 & 33 \\
\hline $\mathrm{R} 4.8$ & $\mathrm{~N}$ & $\mathrm{~N}$ & 20 \\
\hline R4.9 & $\mathrm{S}$ & 17 & 48 \\
\hline $\mathrm{R} 4.10$ & $\mathrm{~N}$ & 1 & 45 \\
\hline $\mathrm{R} 4.11$ & $\mathrm{~N}$ & 0,9 & 50 \\
\hline $\mathrm{R} 4.12$ & $\mathrm{~S}$ & 19 & 40 \\
\hline $\mathrm{R} 4.13$ & $\mathrm{~S}$ & 13 & 42 \\
\hline $\mathrm{R} 4.14$ & $\mathrm{~S}$ & 15 & 44 \\
\hline $\mathrm{R} 4.15$ & $\mathrm{~N}$ & 16 & 22 \\
\hline R4.17 & $\mathrm{N}$ & $\mathrm{N}$ & 20 \\
\hline $\mathrm{R} 4.21$ & $\mathrm{~S}$ & 19 & 55 \\
\hline $\mathrm{R} 4.22$ & $\mathrm{~N}$ & $\mathrm{~N}$ & 19 \\
\hline $\mathrm{R} 4.25$ & $\mathrm{~N}$ & $\mathrm{~N}$ & 14 \\
\hline $\mathrm{R} 4.28$ & $S$ & 21 & 50 \\
\hline $\mathrm{R} 4.29$ & $\mathrm{~S}$ & 16 & 48 \\
\hline $\mathrm{R} 4.31$ & $\mathrm{~N}$ & $\mathrm{~N}$ & 25 \\
\hline $\mathrm{R} 4.33$ & $\mathrm{~S}$ & 14 & 44 \\
\hline $\mathrm{R} 4.34$ & $\mathrm{~N}$ & $\mathrm{~N}$ & 12 \\
\hline $\mathrm{R} 4.37$ & $\mathrm{~S}$ & 0,8 & 35 \\
\hline $\mathrm{R} 4.42$ & $\mathrm{~S}$ & 1 & 23 \\
\hline $\mathrm{R} 4.44$ & $\mathrm{~N}$ & $\mathrm{~N}$ & 16 \\
\hline $\mathrm{R} 4.45$ & $\mathrm{~S}$ & 16 & 30 \\
\hline $\mathrm{R} 4.50$ & $\mathrm{~S}$ & 12 & 25 \\
\hline R4.54 & $\mathrm{S}$ & 13 & 34 \\
\hline R4.57 & $\mathrm{N}$ & $\mathrm{N}$ & 25 \\
\hline
\end{tabular}

nas bactérias isoladas de raízes de milho o genero Bacillus, Burkholderia e Azospirillum foram os mais frequentes totalizando $68 \%$ dos isolados identificados, seguidos de Sphingomonas, Pseudomonas, Herbaspirillum, Pantoea, Bosea. (Tabela 2). Além disso, o predomínio dos gêneros, Bacillus, Burkholderia e Azospirillum nesta avaliação confirmam os resultados de LALANDE (1989) que observou na rizosfera de milho alta porcentagem destes gêneros entre as bactérias; BEvivino et al. (1998) relatam que esses gêneros são geralmente constatados em tecidos internos de plantas e raízes de milho. Os demais grupos 
Tabela 2. Identificação dos isolados pela análise parcial do gene do $16 \mathrm{~S}$ rRNA e similaridade das sequências obtidas com o banco de dados GenBank

\begin{tabular}{|c|c|c|c|c|}
\hline Isolado & Identificação & ID/NCBI & Similaridade & E-value* \\
\hline AbV5 & Azospirillum brasilense & & & \\
\hline AbV6 & Azospirillum brasilense & & & \\
\hline $\mathrm{R} 4.10$ & Azospirillum spp & EU264075 & $97 \%$ & 0.0 \\
\hline $\mathrm{R} 4.12$ & Azospirillum spp & AY692040 & $98 \%$ & $1 e^{-6}$ \\
\hline $\mathrm{R} 4.28$ & Azospirillum spp & DQ664223 & $98 \%$ & 0.0 \\
\hline $\mathrm{R} 4.31$ & Azospirillum spp & AY061963 & $92 \%$ & 0.0 \\
\hline $\mathrm{R} 4.35$ & Azospirillum spp & AF411852 & $95 \%$ & $1 \mathrm{e}^{-6}$ \\
\hline $\mathrm{R} 4.40$ & Azospirillum spp & AB114193 & $93 \%$ & 0.0 \\
\hline $\mathrm{R} 4.44$ & Azospirillum spp & AY321962 & $95 \%$ & 0.0 \\
\hline $\mathrm{R} 4.47$ & Azospirillum spp & AB049112 & $93 \%$ & 0.0 \\
\hline $\mathrm{R} 4.49$ & Azospirillum spp & AY958234 & $92 \%$ & 0.0 \\
\hline $\mathrm{R} 4.3$ & Bacillus spp & AM260980 & $92 \%$ & 0.0 \\
\hline R4.7 & Bacillus spp & AB376080 & $96 \%$ & $1 e^{-3}$ \\
\hline $\mathrm{R} 4.18$ & Bacillus spp & EU809481 & $93 \%$ & $1 e^{-3}$ \\
\hline $\mathrm{R} 4.21$ & Bacillus spp & EU754025 & $95 \%$ & 0.0 \\
\hline $\mathrm{R} 4.34$ & Bacillus spp & EU795037 & $98 \%$ & 0.0 \\
\hline $\mathrm{R} 4.36$ & Bacillus spp & EU809481 & $92 \%$ & $1 e^{-3}$ \\
\hline $\mathrm{R} 4.42$ & Bacillus spp & EU795037 & $98 \%$ & 0.0 \\
\hline $\mathrm{R} 4.50$ & Bacillus spp & DQ397996 & $97 \%$ & $1 e^{-6}$ \\
\hline $\mathrm{R} 4.16$ & Bosea spp & AJ876657 & $97 \%$ & 0.0 \\
\hline $\mathrm{R} 4.27$ & Bosea spp & DQ664253 & $96 \%$ & 0.0 \\
\hline $\mathrm{R} 4.46$ & Bosea spp & DQ303323 & $97 \%$ & $1 \mathrm{e}^{-6}$ \\
\hline $\mathrm{R} 4.6$ & Boseae spp & DQ104981 & $96 \%$ & $1 e^{-3}$ \\
\hline R4.4 & Burkholderia spp & AB366336 & $94 \%$ & $1 e^{-3}$ \\
\hline $\mathrm{R} 4.9$ & Burkholderia spp & AB366336 & $97 \%$ & 0.0 \\
\hline $\mathrm{R} 4.14$ & Burkholderia spp & EU567046 & $96 \%$ & 0.0 \\
\hline $\mathrm{R} 4.22$ & Burkholderia spp & AY949200 & $95 \%$ & 0.0 \\
\hline $\mathrm{R} 4.25$ & Burkholderia spp & EU567046 & $95 \%$ & $1 \mathrm{e}^{-3}$ \\
\hline $\mathrm{R} 4.26$ & Burkholderia spp & AB366362 & $95 \%$ & $1 e^{-6}$ \\
\hline $\mathrm{R} 4.38$ & Burkholderia spp & AY949200 & $92 \%$ & 0.0 \\
\hline $\mathrm{R} 4.41$ & Burkholderia spp & AB272342 & $92 \%$ & $1 e^{-6}$ \\
\hline $\mathrm{R} 4.45$ & Burkholderia spp & DQ150551 & $97 \%$ & $1 e^{-3}$ \\
\hline $\mathrm{R} 4.5$ & Herbaspirillum spp & EU549846 & $98 \%$ & $1 e^{-3}$ \\
\hline $\mathrm{R} 4.13$ & Herbaspirillum spp & AB027694 & $93 \%$ & 0.0 \\
\hline $\mathrm{R} 4.29$ & Herbaspirillum spp & EU244722 & $97 \%$ & 0.0 \\
\hline $\mathrm{R} 4.33$ & Herbaspirillum spp & DQ150556 & $97 \%$ & 0.0 \\
\hline $\mathrm{R} 4.11$ & Pantoea spp & EU816767 & $95 \%$ & $1 e^{-6}$ \\
\hline $\mathrm{R} 4.17$ & Pantoea spp & EU816763 & $93 \%$ & $1 e^{-3}$ \\
\hline $\mathrm{R} 4.23$ & Pantoea spp & EU816766 & $97 \%$ & 0.0 \\
\hline $\mathrm{R} 4.32$ & Pantoea spp & DQ131851 & $92 \%$ & $1 e^{-3}$ \\
\hline $\mathrm{R} 4.37$ & Pantoea spp & DQ847332 & $92 \%$ & $1 e^{-3}$ \\
\hline $\mathrm{R} 4.43$ & Pantoea spp & EU741019 & $92 \%$ & 0.0 \\
\hline $\mathrm{R} 4.2$ & Pseudomonas spp & EU073118 & $93 \%$ & 0.0 \\
\hline $\mathrm{R} 4.15$ & Pseudomonas spp & AB272375 & $92 \%$ & $1 e^{-6}$ \\
\hline $\mathrm{R} 4.20$ & Pseudomonas spp & EU073071 & $93 \%$ & $1 e^{-6}$ \\
\hline $\mathrm{R} 4.24$ & Pseudomonas spp & EU073117 & $93 \%$ & $1 e^{-3}$ \\
\hline $\mathrm{R} 4.30$ & Pseudomonas spp & EU836725 & $96 \%$ & $1 e^{-6}$ \\
\hline $\mathrm{R} 4.39$ & Pseudomonas spp & EU841536 & $93 \%$ & $1 e^{-6}$ \\
\hline $\mathrm{R} 4.48$ & Pseudomonas spp & EU836171 & $93 \%$ & $1 e^{-3}$ \\
\hline $\mathrm{R} 4.1$ & Sphingomonas spp & EU 629211 & $92 \%$ & 0.0 \\
\hline $\mathrm{R} 4.8$ & Sphingomonas spp & EU629211 & $97 \%$ & 0.0 \\
\hline R4.19 & Sphingomonas spp & AB299583 & $98 \%$ & 0.0 \\
\hline
\end{tabular}

*E-value: Quanto menor o E-value mais significativo é o alinhamento. 
são: Sphingomonas, Herbaspirillum, Pseudomonas, Pantoea e Bosea, isolados com certa frequência de várias culturas.

Os 27 isolados com resultados positivos para solubilização de fosfato foram submetidos ao teste da produção de AIA. Devido à sua facilidade, rapidez, sensibilidade e custo, o reagente de Salkowsky têm sido amplamente empregado na detecção do AIA produzido por bactérias diazotróficas e fitopatogênicas. (STEENHOUD e VANDERLEYDEN, 2000). A detecção da produção de AIA foi realizada no sobrenadante das culturas onde se notou DO de 0,8, 1,5 e 3,5 após diferentes tempos de cultivo. Essa análise revelou que, apesar da grande variação na quantidade de AIA produzido nos ensaios, a maior produção de AIA ocorreu após as 24 horas e pode ser detectada em apenas 18 isolados (Tabela 3). Verificou-se que dos isolados produtores de AIA, além dos padrões (estirpes AbV5 e AbV6), quatro pertencem ao gênero Azospirillum (R4.10, R4.12, R4.28, R4.44), dois a Sphingomonas (R4.1 e R4.8), dois a Pantoea (R4.11 e R4.17), três a Burkholderia (R4.4, R4.9, R4.22), três a Bacillus (R4.21, R4.34, R4.42) e quatro a Herbaspirillum (R4.10, R4.12, R4.28, R4.44).

Nos isolados pertencentes ao gênero Azospirillum (R4.10, R4.12), houve dosagens menores de AIA em relação ao controle positivo (estirpes AbV5 e AbV6). Por outro lado os isolados (R4.28, R4.44) apesar de nos estágios iniciais ocorrer concentrações menores de AIA que os padrões, no fim da análise são produtores similares desse composto (Tabela 3). Essa variação quantitativa de produção de AIA entre isolados de Azospirillum já está descrita por RADWAN et al. (2004). Esses autores atestam que diversas linhagens de Azospirillum produziram quantidades diferentes de compostos indólicos, e que nas linhagens de Azospirillum brasilense constataram níveis mais elevados em relação às linhagens de Azospirillum lipoferum.

OsisoladosdeHerbaspirillumspp(R4.13,R4.29,R4.33) produziram AIA a partir do primeiro dia de crescimento, em média $13 \mu \mathrm{g} \mathrm{mL}^{-1}$ de AIA na cultura, exceto o isolado R4.50 com níveis muito baixos de produção de AIA (1,23 $\mu \mathrm{g} \mathrm{mL}^{-1}$ de AIA). Os microrganismos pertencentes a este gênero tiveram dosagens semelhantes entre eles, nas primeiras 24 horas de crescimento, e além disso, as dosagens foram menores que nos controles positivos, nas 48-72 horas de crescimento. Dados apresentados por RADWAN et al. (2004), também relatam menor produção de AIA por isolados de Herbaspirillum em relação às linhagens de Azospirillum.

Tabela 3. Dosagem colorimétrica do AIA em diferentes estágios de cultivo em meio DYGS suplementado com $100 \mu \mathrm{g} \mathrm{mL}^{-1}$ de triptofano em D. ${ }_{600}$ aproximada de 0,8 (12-24 hs de crescimento),1,5 (24-48 hs de crescimento) e $\geq 3,5$ (48-72 hs de crescimento)

\begin{tabular}{|c|c|c|c|c|c|c|}
\hline \multirow[t]{2}{*}{ Isolados } & \multicolumn{2}{|c|}{ D.O. $_{600}(0,8)$} & \multicolumn{2}{|c|}{ D.O. $_{600}(1,5)$} & \multicolumn{2}{|c|}{ D.O ${ }_{600}(\geq 3,5)$} \\
\hline & $\mathrm{UFCX}^{2} 0^{8}$ & AIA & UFC $\times 10^{10}$ & AIA & UFC $\times 10^{12}$ & AIA \\
\hline & & $\mu \mathrm{g} \mathrm{mL}^{-1}$ & & $\mu \mathrm{g} \mathrm{mL}^{-1}$ & & $\mu \mathrm{g} \mathrm{mL}^{-1}$ \\
\hline AbV5 & $2,5 \times 10^{8}$ & 8,35 & $8,0 \times 10^{10}$ & 42,5 & $2,0 \times 10^{12}$ & 68 \\
\hline AbV6 & $1,8 \times 10^{8}$ & 7,87 & $5,0 \times 10^{10}$ & 38,3 & $2,8 \times 10^{12}$ & 70 \\
\hline $\mathrm{R} 4.1$ & $1,3 \times 10^{8}$ & 7,73 & $6,1 \times 10^{10}$ & 40,2 & $3,2 \times 10^{12}$ & 72 \\
\hline R4.4 & $3,0 \times 10^{8}$ & 2,88 & $7,0 \times 10^{10}$ & 32,0 & $5,0 \times 10^{12}$ & 38 \\
\hline $\mathrm{R} 4.8$ & $3,0 \times 10^{8}$ & 2,41 & $5,0 \times 10^{10}$ & 29,0 & $2,0 \times 10^{12}$ & 80 \\
\hline R4.9 & $3,0 \times 10^{8}$ & 3,13 & $5,0 \times 10^{10}$ & 32,3 & $2,0 \times 10^{12}$ & 65 \\
\hline $\mathrm{R} 4.10$ & $2,7 \times 10^{8}$ & 1,98 & $5,0 \times 10^{10}$ & 17,8 & $5,0 \times 10^{12}$ & 37 \\
\hline $\mathrm{R} 4.11$ & $3,0 \times 10^{8}$ & 6,34 & $5,0 \times 10^{10}$ & 13,0 & $7,0 \times 10^{12}$ & 53 \\
\hline $\mathrm{R} 4.12$ & $2,0 \times 10^{8}$ & 2,08 & $4,5 \times 10^{10}$ & 29,6 & $3,0 \times 10^{12}$ & 33 \\
\hline $\mathrm{R} 4.13$ & $3,5 \times 10^{8}$ & 13,50 & $3,8 \times 10^{10}$ & 31,3 & $4,3 \times 10^{12}$ & 40 \\
\hline $\mathrm{R} 4.17$ & $3,2 \times 10^{8}$ & 4,39 & $5,0 \times 10^{10}$ & 26,5 & $5,0 \times 10^{12}$ & 30 \\
\hline $\mathrm{R} 4.21$ & $2,8 \times 10^{8}$ & 2,80 & $3,7 \times 10^{10}$ & 14,8 & $3,0 \times 10^{12}$ & 110 \\
\hline $\mathrm{R} 4.22$ & $1,5 \times 10^{8}$ & 2,64 & $3,0 \times 10^{10}$ & 36,3 & $5,0 \times 10^{12}$ & 62 \\
\hline $\mathrm{R} 4.28$ & $1,3 \times 10^{8}$ & 3,15 & $3,2 \times 10^{10}$ & 32,0 & $0,5 \times 10^{12}$ & 67 \\
\hline $\mathrm{R} 4.29$ & $0,8 \times 10^{8}$ & 14,70 & $6,2 \times 10^{10}$ & 32,4 & $1,0 \times 10^{12}$ & 43 \\
\hline $\mathrm{R} 4.33$ & $6,0 \times 10^{8}$ & 13,80 & $4,0 \times 10^{10}$ & 28,3 & $2,6 \times 10^{12}$ & 65 \\
\hline R4.34 & $4,0 \times 10^{8}$ & 2,41 & $5,0 \times 10^{10}$ & 21,8 & $3,2 \times 10^{12}$ & 108 \\
\hline $\mathrm{R} 4.42$ & $3,6 \times 10^{8}$ & 2,23 & $7,0 \times 10^{10}$ & 68,3 & $2,0 \times 10^{12}$ & 104 \\
\hline R4.44 & $0,8 \times 10^{8}$ & 2,65 & $4,0 \times 10^{10}$ & 25,3 & $3,0 \times 10^{12}$ & 87 \\
\hline $\mathrm{R} 4.50$ & $2,8 \times 10^{8}$ & 1,23 & $6,5 \times 10^{10}$ & 18,5 & $2,0 \times 10^{12}$ & 31 \\
\hline
\end{tabular}


Tabela 4. Massa da parte aérea e radicular e altura de plantas de milho inoculadas com diferentes bactérias

\begin{tabular}{|c|c|c|c|c|}
\hline \multirow{2}{*}{ Tratamento } & \multicolumn{2}{|c|}{ Massa seca } & \multicolumn{2}{|c|}{ Altura planta } \\
\hline & parte aérea & raiz & 20 dias & 70 dias \\
\hline & 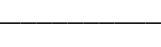 & - & - _ & - \\
\hline R4.1 & $9,89 \mathrm{~b}$ & $2,18 \mathrm{~b}$ & $25,17 \mathrm{~b}$ & $90,14 \mathrm{~b}$ \\
\hline AbV5 e AbV6 & $11,50 \mathrm{a}$ & $2,75 \mathrm{a}$ & $30,71 \mathrm{a}$ & $98,71 \mathrm{a}$ \\
\hline Sem inoculo & $7,47 \mathrm{c}$ & $1,62 \mathrm{c}$ & $18,57 \mathrm{c}$ & $86,29 \mathrm{c}$ \\
\hline $\mathrm{CV}$ & 6,35 & 17,62 & 5,20 & 2,86 \\
\hline
\end{tabular}

${ }^{*}$ letras diferentes representam diferenças entre as medias estatisticamente significantes

Nos isolados pertencentes aos gêneros Sphingomonas (R4.1 e R4.8) a dosagem foi semelhante ao controle positivo nos diferentes tempos, e no grupo das Burkholderias (R4.4, R4.9, R4.22) e Pantoea (R4.11 e R4.17) as dosagens estiveram próximas de AIA entre si, mas inferiores quando comparadas ao controle positivo. Por outro lado os três isolados pertencentes ao gênero Bacillus (R4.21, R4.34, R4.42) tiveram dosagens de AIA muito superiores ao controle positivo e aos demais gêneros nas 48-72 horas de crescimento.

Os organismos utilizados no presente trabalho apresentaram capacidade diferenciada na produção de AIA, conforme já relatados por TIEN et al. (1979) e HaRTMAnN et al. (1983). Inúmeras variações para o teste de Salkowsky (MAYER, 1958) são comumente constatadas na literatura para a detecção de compostos indólicos produzidos por bactérias, entre eles, AIA (BAlota et al., 1995). Entretanto PATten e Glick (1996) relataram que alguns organismos tais como Gluconacetobacter spp, Acinetobacter spp, Actinomyces spp, Agrobacterium spp, Azospirillum spp, Bacillus spp, Burkholderia spp, Curtobacterium spp, Pantoea spp, Pseudomonas spp e Xanthomonas spp podem promover o crescimento vegetal aumentando o comprimento das raízes e o número de pelos radiculares. TIEN et al. (1979) relataram que esse efeito é atribuído à produção microbiana de hormônios vegetais ou reguladores do crescimento vegetal.

Devido ao gênero Sphingomonas ter sido muito pouco empregado em ensaios de promoção de crescimento vegetal, o isolado R4.1 pertencente a este gênero e cuja produção de AIA é equivalente ao controle positivo foi o escolhido entre os isolados estudados para o teste de eficiência em plantas de milho. A tabela 4 indica que a MSPR dos tratamentos em relação ao controle positivo foram semelhantes. As raízes das plantas inoculadas com o isolado R4.1 ficaram mais alongadas e com pouca presença de pêlos radiculares, ao contrário do controle positivo com números elevados de raízes secundárias e de pelos radiculares.
Por outro lado, observou-se diferença significativa em relação à altura dessas plantas quando comparada ao controle positivo. As plantas submetidas à inoculação com as estirpes de Azospirillum brasilense (AbV5 e AbV6) ficaram mais altas e vigorosas o que não foi observado para a planta inoculada com o isolado R4.1, consequentemente, na massa seca da parte aérea da planta houve diferenças. Este fato indica que o isolado R4.1 identificado como Sphingomonas interferiu em algum estágio de desenvolvimento da planta, podendo ser a interação entre genótipo da planta e a bactéria, adaptação às condições ambientais, tipo de solo, $\mathrm{pH}$ entre outros.

Em trigo, BALDANi e DöBEREINER (1980) e BALDANI et al. (1986) testaram diversas isoladas e concluíram que as da mesma espécie vegetal (homólogas) foram mais eficientes do que as provenientes de plantas de espécies diferentes.

O mecanismo de promoção de crescimento vegetal por microrganismos endofíticos ainda necessita de mais estudos para melhor entendimento dos fatores envolvidos. A interação entre o genótipo da planta e a comunidade endofítica promotora de crescimento e outros fatores podem interagir neste processo, como as comunidades microbianas epifíticas e da rizosfera.

\section{CONCLUSÃO}

$\mathrm{O}$ isolado $\mathrm{R} 4.1$ é responsivo aos testes realizados podendo tornar-se um organismo promissor como PGPRs em comparação ao Azospirillum brasilense.

\section{AGRADECIMENTOS}

À Comissão Nacional de Pesquisa (CNPq) pela concessão da bolsa de Doutorado e à Fundação de Amparo a Pesquisa do Estado de São Paulo (FAPESP) pelo auxílio à pesquisa (Proc. 07/54070-9).

\section{REFERÊNCIAS}

AGRIANUAL - Anuário da Agricultura brasileira. São Paulo: FNP Consultoria \& Agroinformativa, 2004. 200p. 
BALDANI, J.I; BALDANI, V.L.D.; SELDIN, L.; DOBEREINER, J. Characterization of Herbaspirillum seropedicae gen. Nov., sp. nov., a Root-Associated Nitrogen Fixation Bacterium. International Journal of Systematic Bacteriology, v.36, p.8693, 1986.

BALDANI, V.L.D.; DOBEREINER, J. Host plant specificity in the infection of cereals with Azospirillum spp. Soil Biology and Biochemistry, v.12, p.433-439, 1980.

BALOTA, E.L.; LOPES, E.S.; HUNGRIA, M.; DOBEREINER, J. Interações e efeitos fisiológicos de bactérias diazotróficas e fungos micorrízicos arbusculares na mandioca. Pesquisa Agropecuária Brasileira, v.30, p.1335-1345,1995.

BEVIVINO, A.; SARROCCO, S.; DALMASTRI, C.; TABACCHIONI, S.; CANTALE, C.; CHIARINI, L. Characterization of a free-living maize-rhizosphere population of Burholderia cepacia : effect of seed treatment on disease suppression and growth promotion of maize. FEMS Microbiology Ecology, v.27, p.225-237, 1998.

BORÉM, A. Melhoramento de espécies cultivadas. Viçosa: UFV, 1999.

BRIC, J.M.; BOSTOCK, R.M.; SILVESTONE, S.E. Rapid in situ assay for indoleacetic acid production by bacteria immobilized on a nitrocellulose membrane. Applied Environmental Microbiology, v.57, p.535-538, 1991.

DÖBEREINER, J.; BALDANI, V.L.D.; BALDANI, J.I. Como isolar e identificar bactérias diazotróficas de plantas não leguminosas. Brasília : Embrapa-SPI, 1995. 60p.

GORDON, S.A.; WEBER, R.P. Colorimetric estimation of indoleacetic acid. Plant Physiology, v.26, p.192-195, 1951.

HARTMANN, A.; SINGH, M.; KLINGMULLER, W. Isolation and characterization of Azospirillum mutants excreting high amounts of indole acetic acid. Canadian Journal Microbiology, v.29, p.916-923, 1983.

LALANDE, R.; BISSONNETTE, N.; COUTLEÉ, D.; ANTOUN, $\mathrm{H}$. Identification of rhizobacteria from maize and determination of their plant-growth promoting potencial. Plant and Soil, v.115, p.7-11, 1989.

MARMUR, J. A. Procedure for isolation of deoxyribonucleic acid from microorganisms. Journal Molecular Biology, v.3, p.208-218, 1961.

MAYER, A.M. Determination of indole acetic acid by the Salkowsky reaction. Nature, v.162, p.1670-1671, 1958.

McINROY, J.A.; KLOEPPER, J.W. Analisys of population densities and identication of endophytic bacteria of maize and cotton in the field. Kew Bulletin, v.14, p.328-331, 1991.

NAUTIYAL, C.S. An effect microbiological grouwth medium for screening phosphate solubilizing microorganisms. FEMS Microbiology Letters, v.70, p.265-270, 1999.

PATTEN, C.L.; GLICK, B.R.. Bacterial biosynthesis of indole3-acetic acid. Canadian Journal Microbiology, v.42, p.207220, 1996.

RADWAN, T. El-SAYED El-DESOUK, MOHAMED, Z.K.; REIS, V.M. Efeito da inoculação de Azospirillum e Herbaspirillum na produção de compostos indólicos em plântulas de milho e arroz. Pesquisa Agropecuária Brasileira. v.39, p.987-994, 2004.

RAVEN, P.H; EVERT, R.F.; EICHHORN, S.E. Regulando o crescimento e o desenvolvimento: os hormônios vegetais. In: RAVEN, P.H; EVERT, R.F.; EICHHORN, S.E. (Ed.). Biologia Vegetal. Rio de Janeiro: Guanabara Koogan, 2001. p.646-675.

RODRÍGUEZ, H.; FRAGA, R. Phosphate solubilizing bacteria and their role in plant growth promotion. Biotechnology Advances, v.17, p.319-339, 1999.

STEENHOUDT, O.; VANDERLEYDEN, J. Azospirillum, a free-living nitrogen-fixing bacterium closely associated with grasses: genetic, biochemical and ecological aspects. FEMS Microbiology Reviews, v.24, p.487-506, 2000.

TIEN, T.M.; GASKIN, M.H.; HUBBELL, D.H. Plant growth substances produced by Azospirillum brasilense and their effect on growth of pearl millet (Pennisetum americanum L.) Applied and Enviromental Microbiology, v.37, p.1016-1024, 1979. 
